\title{
Systemic and local effects of disportional longitudinal growth of bones in foals and lambs and the impact on bone mineral density and content
}

\author{
Annette Liesegang ${ }^{1}$, Regula Giezendanner', Sylvie Tanner², Brigitte von Rechenberg² and Jörg Aver ${ }^{3}$ \\ Institute of Animal Nutrition', Musculoskeletal Research Unit, Equine Department ${ }^{2}$ and Equine Department ${ }^{3}$, Vetsuisse Faculty ZH, University of Zürich, Switzer- \\ land
}

\begin{abstract}
Summary
In the present study the effects of "periosteal stripping" on bone and cartilage metabolism of foals with angular limb deformities and healthy experimental lambs were examined. Five foals with angular limb deformities were treated surgically by means of "hemicircumferential transection of the periosteum and periosteal stripping" (HCTP/HP). Before surgery as well as twice after surgery, $1,25(\mathrm{OH})_{2} \mathrm{Vitamin} \mathrm{D}, \mathrm{bone}$ and cartilage markers in the serum were determined and compared to 5 healthy foals of the same age. In addition 10 healthy lambs were treated by HCTP/HP, in which the same parameters and bone density were determined. At 22 days after surgery the lambs were sacrificed and treated and control bones were sampled and processed for immunohistochemistry. Neither in foals nor in lambs, significant differences could be observed between treated and untreated animals with regard to the parameters measured in serum. Nevertheless, both treated groups revealed a tendency for higher bone remodelling compared to control animals. This could be the result of an increased bone remodelling rate following surgery. No statistically significant difference in bone mineral density between treated and untreated animals could be detected. In contrast local changes of signal transduction related to parathyroid hormone related protein and indian hedgehog (PTHrP/lhh) were observed using immunhistochemistry. It was concluded that HCTP/HP at the level of epiphysis and metaphysis does not lead to systemic effects, even though local events detected by immunohistochemistry point to an increased bone formation at the treated site.
\end{abstract}

Keywords: Periostal stripping, foal, lamb, long bone growth, bone mineral density, bone mineral content, bone markers

Systemische und lokale Auswirkungen disproportionalen, longitudinalen Knochenwachstums bei Fohlen und Lämmern und die Bedeutung von Dichte und Gehalt an Knochenmineralien

In der vorliegenden Arbeit wurden die Auswirkungen des "Periost stripping" auf den Knochenstoffwechsel von Fohlen mit Achsenfehlstellungen und Lämmern untersucht. Fünf Fohlen mit Achsenfehlstellungen wurden mittels "Hemicircumferential transection of the periosteum and periosteal stripping" (HCTP and PS) operiert. Vor der Operation sowie 10 und 22 Tage danach wurden bei ihnen sowie bei fünf gleichaltrigen, gesunden Kontrollfohlen 1,25(OH) 2 Vitamin D, Knochen- und Knorpelmarker im Serum bestimmt. 10 gesunde Lämmer wurden ebenfalls mittels HCTP and PS operiert. Vor der Operation sowie 2, 6, 10, 14, 18 und 22 Tage danach wurde bei ihnen sowie bei 10 gleichaltrigen, gesunden Kontrolltieren 1,25(OH) 2 Vitamin D, Knochen- und Knorpelmarker im Serum bestimmt sowie Knochendichte und -mineralgehalt mittels pQCT gemessen. Nach der Schlachtung 22 Tage nach der Operation wurden die operierten Knochen sowie die entsprechenden Knochen der Kontrolltiere entnommen und später immunhistologisch aufbereitet. Weder bei den Fohlen noch bei den Lämmern konnten bezüglich der Parameter im Serum signifikante Unterschiede zwischen operierten und nicht operierten Tieren festgestellt werden. Allerdings wiesen sowohl die operierten Fohlen als auch die operierten Lämmer deutlich höhere OC/ICTP-Quotienten auf als die nicht operierten Kontrolltiere, was auf eine erhöhte Knochenumbaurate als Folge der Operation schliessen lässt. Die Bestimmung von Knochendichte und -mineralgehalt bei den Lämmern ergab keine signifikanten Unterschiede zwischen operierten und nicht operierten Tieren. Es wird vermutet, dass der Eingriff mittels HCTP and PS zu minim ist, um systemische Effekte nachzuweisen. Auf lokaler Ebene deuten die Auswertungen der mittels Immunhistochemie detektierten lokalen Wachstumsfaktoren darauf hin, dass HCTP and PS an der operierten Stelle zu vermehrtem Knochenaufbau führen könnte.

Schlüsselwörter: Periostal stripping, Fohlen, Lamm, Knochenwachstum, Knochendichte, Mineralstoffgehalt, Knochenmarker

\section{Introduction}

Periosteal transection and elevation is a surgical method aimed at correcting disproportionate growth and/or premature closure thereof in young foals (Aver 2004). Disturbances of the growth plates due to trauma or also for unknown reasons (Caron 1988) can cause a halt in longitudinal growth of bones with subsequently premature ossification of the growth plate, since microfractures in the proliferation and maturation zone of the epiphyses are the result. These changes lead to early maturation of the chondrocytes and premature mineralization of the affected growth plate. The consequence may be a shortening of the limbs, if both sides are equally affected, or to axial deviations due to incongruent growth of the lateral and medial aspects of the bone, respectively. The limb will deviate to the side where the premature closure occurs and severely disturb the longitudinal axis of the entire limb. Apart from the fact that it may mechanically alter the gaits, it will inevitably lead to disproportionate mechanical loading of the joint cartilages especially in the lower extremity. This focal overload of some aspects of the articular cartilage will subsequently lead to the onset of (still incurable) osteoarthritis and joint degeneration already at a young age. Therefore, a surgical method to correct such growth incongruencies in young animals has been developed already in the eighties, where surgical transection and elevation of the periosteum/perichondrium was used to stimulate the proliferating zone to 
resume and catch up with longitudinal growth while at the same time inhibiting premature ossification of the growth plate (Aver and Martens 1982, Aver 2004, Aver and Rechenberg 2006). Although clinical studies showed efficiency of this surgical regimen, the true mechanism of the corrective procedure was never shown. It is still unclear, whether local or systemic effects alone, or both together are causing the accelerated growth of the affected growth plate.

Parathyroid hormone related protein (PTHrP) and its receptors (PTHR) as well as Indian hedgehog (lhh) and the transforming growth factor $\beta$ (TGF) and fibroblast growth factor (FGF) were demonstrated to be involved in physiological development and growth of long bones in mice (van der Eerden 2003, Vortkamp 2003). In earlier research studies with experimental lambs (see manuscript B.von Rechenberg) local changes in signal transduction within the growth plate and adjacent perichondrium after HCTP/HP were demonstrated to be related to the negative feedback loop mechanism between parathyroid hormone like protein (PTHrP), the PTH/PTHrP receptor 1 (PTHrPR 1) and Indian hedgehog (Ihh) (Stevens and Williams 1999, Nilsson et al. 2005).

On a more systemic level parathyroid hormone (PTH) secreted from the parathyroidea plays an important (systemic) role on the mineral metabolism and bone remodelling (Bushinsky and Monk 1998). It increases blood calcium levels by accelerating bone resorption. Until today its role has never been used to evaluate the etiology of physeal changes related to axial deviations. However, it has been widely used in the context with other orthopedic problems in horses. Along that line, bone turnover, especially the up-regulation of bone formation was measured by the help of biochemical markers for bone cell activity such as osteocalcin (Lepage et al. 1998) or for bone resorption markers as carboxyterminal cross-linked telopeptide of type I collagen and the carboxyterminal telopeptide without cross-linking (Lepage et al. 1998). Again, also these markers were never studied in the context of axial deviations. In addition, the degradation and formation markers of collagen type II, which are mainly found in cartilage tissue, were measured to evaluate cartilage metabolism, but also not in context with axial deviations in foals. For both tissues, the ratio of bone (or cartilage) resorption and formation markers can be used to objectify the remodelling of these tissues.

Last but not least, parameters influencing the mechanical properties of bone may also influence the correct growth of long bones in foals, but were never measured in relation to axis deviation. Bone strength was shown to depend on the amount and density of bone present. On the basis of this relationship several techniques have been developed to measure the bone mineral density (BMD) and the bone mineral content (BMC) non-invasively at different skeletal sites. Peripheral quantitative computed tomography ( $\mathrm{QQCT}$ ) have become established methods for evaluating the skeletal status, assessing osteoporosis, determining fracture risk, and monitoring metabolic diseases and therapies in humans (Falkner et al. 1991). In veterinary medicine, the application of $\mathrm{pQCT}$ technology is still rare, although these methodologies have the potential to be important research and clinical tools for e.g. the study of endocrine and metabolic diseases that affect the calciumphosphorus balance, orthopedic diseases and fracture risks. Therefore, the goal of this study was to investigate whether the hormonal metabolism is changed in subjects, in which longitudinal growth is stimulated by different local factors. The study was based on the hypothesis that in HCTP/HP bone formation will be up regulated, while bone resorption will not be changed.

\section{Materials and methods}

Twenty weaned two months old lambs (10 male, 10 female) were used in this study, from which 5 males and 5 females (group op) underwent periosteal stripping at the distal lateral radius, tibia, metacarpus and metatarsus for systemic investigation of biomarkers of bone/cartilage metabolism. Bones were harvested at 22 days post-surgery. The growth plates were cut in a latero-medial fashion, where the non-operated medial site of the same bone served as internal control. The other 10 animals were not surgically treated and used as independent control animals. The animals weighed $17.0 \pm 0.7 \mathrm{~kg}$, when surgery was performed, and 19.5 \pm 0.7 $\mathrm{kg}$ at the end of the experiment, respectively. Blood samples and bone mineral densities were collected and measured, respectively, on day -1 (before surgery), day 0 (surgery) and then $2,6,10,14,18$ and 22 days post surgery.

In addition, five foals with axial deviations, which were operated at the horse clinic of the Vetsuisse Faculty Zurich with periost-stripping, were used ( 2 male, 3 female). Five healthy, age-matched foals were used as controls (4 male, 1 female). The foals were 3 weeks old on average (STE \pm 2.3 days). Blood samples were collected before surgery, 10 and 21 days post-surgery.

Determination of 1,25-(OH) 2 Vitamin D, osteocalcin, crosslaps I, procolagen II, crosslaps II in serum

Serum was analyzed for Crosslaps, ICTP, OC (Metra ${ }^{\circledR}$ Osteocalcin Enzyme Immunoassay Kit, Quidel Corporation, McKellar Court, California, USA), CPII (Frisbie et al. 1999, Laverty et al. 2000, Billinghurst et al. 2004) and 1.25VitD (1,25-Dihydroxy Vitamin D RIA, Immunodiagnostics Systems Ltd, Boldon UK) as previously described (Liesegang et al. 2000, Liesegang and Risteli 2005, Liesegang et al. 1998). To calculate the bone remodeling rate, the ratio of OC to ICTP was used.

\section{Bone mineral density and bone mineral content}

After measuring the length of the left metatarsus of the living animals, total BMD and BMC were measured with $\mathrm{PQCT}$ (Stratec XCT 960A bone scanner; Stratec Medizinaltechnik $\mathrm{GmbH}$, Pforzheim, Germany; Gasser 2002). The measurements were performed in the middle of the diaphysis $150 \%$ of the length of metatarsus). Additionally the distal epiphysis was measured ( $90 \%$ of the length of metatarsus). Cortical BMC and BMD were calculated by automated computation (Cortical mode 2; threshold for cortical bone $>640 \mathrm{mg} / \mathrm{cm}^{3}$ ).

\section{Immunohistochemistry}

Obviously, immunhistochemistry could only be performed in bones of the experimental lambs. After slaughtering, $3 \mathrm{~mm}$ 
thick sections of the tibiae and radii were cut distally from the lateral to the medial aspect and parallel to the frontal plane of the bones using a band saw (Fig. 1). The samples were then fixed in $4 \%$ freshly prepared and buffered $4 \%$ formaldehyde (Fluka Chemie AG, Buchs, Switzerland) for 2 days, followed by decalcification in 12\% EDTA (Ethylendiamin Tetraessigsäure Dinatriumsalz 12\%, pH 7, Fluka Chemie AG, Buchs, Switzerland) at room temperature and constant stirring for at least 36 to 56 days. When decalcification was complete, samples were embedded in paraffin according to our routine protocol. Six sections were cut from each block, of which one was used for routine hematoxylin-eosin (HE) staining, whereas the others were used for immunohistochemical procedures using

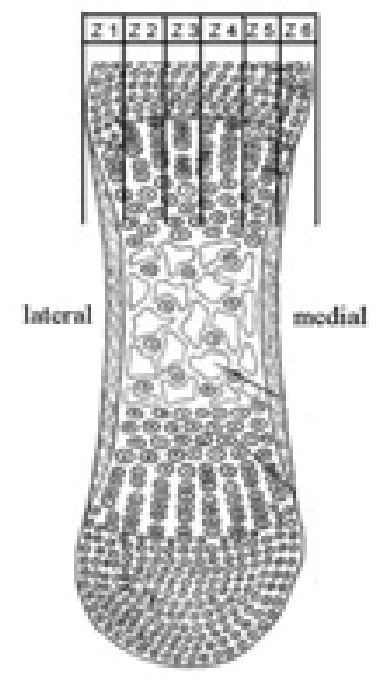

Fig. 1 The different zones of the analyzed epiphysis (Z) 1-6 from lateral to medial

antibodies against the appropriate protein (Ihh, PTHrP, PTHR, FGF, TGF). Rabbit anti Ihh (dilution 1:3; Indian Hedge Hog, H88; Santa Cruz Biotechnology Inc., Santa Cruz, California, USA), mouse anti PTHR Type 1 (dilution 1: 10; Parathyroid-Lab Vision/NeoMarkers), rabbit anti PTHrP (H 137) (Dilution 1:3, Santa Cruz Biotechnology), rabbit anti basic FGF-2 (Dilution $1: 1000$, Chemicon) and a mouse anti Human TGF- $\beta$ antibodies (Dilution 1:100, Chemicon) were used. All subsequent steps were carried out at room temperature following routine immunhistochemical protocols (see von Rechenberg et al. 2010). Briefly, after deparaffination, slides were rehydated and endogenous peroxidases inactivated using $3 \% \mathrm{H}_{2} \mathrm{O}_{2}$. Protein blocks were applied (Dako Cytomation Proteon block X0909) before Avidin and Biotin blockage (Avidin Biotin Blokking Kit SP-2001, Vector Laboratories, USA). Incubation with antibodies was overnight when the secondary antibody (LSAB + Kit, K5003, HRP/AEC, Rabbit/Mouse) and the chromogen AEC (Aminoethyl Carbazole Substrate Kit, Invitorgen, 00-2007) was used for antibody detection. Negative controls were performed using TBS instead of primary antibody and positive controls employing sheep lung for TGF- $\beta$, bone of sheep fetus for thh and PTHrP, granulaton tissue of a horse for FGF and mammary tissue of a sheep for PTHR. For microscopic analysis of the slides a light microscope (Leica DMLB, Leica Microsystems AG, Glattbrugg, Switzerland) was used. Following histomorphological examination, the slides were assessed semiquantitatively individually analyzing epiphyses in six zones (Fig. 1).
First of all the cells were analyzed for positive staining yes or no. After that, the number of positive stained cells in the different zones (proliferative and hypertrophic zone or resting zone) were quantified semiquantitatively $(0=$ no cells stained; $1=$ one fourth of the cells stained; $2=$ half of the cells stained; 3 = three quarters of the cells stained; $4=$ all cells stained). More staining means higher activity of the cells.

\section{Statistics}

The results are presented as mean \pm standard error (SE). A multivariate analysis of variance for repeated measures (ANOVA) was performed with group as a cofactor included in the model to test difference of the time dependent patterns between the groups. To avoid false conclusions due to a violation of the assumption of compound symmetry, a HuynhFeldt correction was performed. The statistical differences between the sampling days within the species were analyzed with a Wilcoxon's sign rank test for paired samples. Furthermore, the difference between groups was tested with the MannWhitney $U$ test (non-parametric) to limit the influence of extreme values. The level of significance was set at $p=0.05$ for all tests. All statistical analyses were performed by use of SYSTAT ${ }^{\circledR}$ for Windows ${ }^{\circledR}$ (Version 1 1.0, SPSS Inc. Chicago, IL). The results of the semiquantitative scorings of the immunohistochemistry were analysed with a factorial analysis of variance. In addition, mean and standard deviations were calculated for the descriptive statistic (SPSS Version 11.0). The pvalue was set at $p<0.05$.

\section{Results}

Mean concentrations of $1,25(\mathrm{OH})_{2}$ Vitamin $\mathrm{D}$ in serum of lambs and foals

Lambs

There was a tendency to increased mean Vitamin D (Vit D) concentrations in the op group compared to the control group. Both groups revealed lower concentration at the end of the experiment (Fig. 2a). Over time a significant decrease was observed in both groups $(p<0.05)$.

\section{Foals}

The mean $1,25(\mathrm{OH})_{2}$ Vitamin $\mathrm{D}\left(1,25(\mathrm{OH})_{2}\right.$ VitD) concentrations increased in both groups with time, although no significant difference between the groups was observed, the increase of the concentrations in the op group seemed to be less distinct (Fig. 2b).

\section{Mean OC/ICTP Ratios}

Lambs

The ratio of OC to ICTP is characterizing bone remodeling. The values within the op group increased until day 14, which indicates an increased bone formation (Fig 3a). Interestingly, the control animals revealed a continuing decrease, which is physiological in growing animals. There was a tendency to increased bone remodeling when comparing op and control group ( $p=0.1$, day 14). 
Foals

In the foals, the ratio of the operated foals increased during the experimental period, while the control animals revealed higher values at the beginning. At the end of the experiment both groups nearly had comparable values. Although the values in the op animals were lower at the beginning, no significant differences between the groups were observed (Fig.3b).

\section{Mean CPII/CTX-II Ratios}

Lambs

With the ratio of CPII/CTX-II cartilage remodeling may be rated. The cartilage remodeling increased with the time in both groups. No group effects were revealed (fig. 4a).
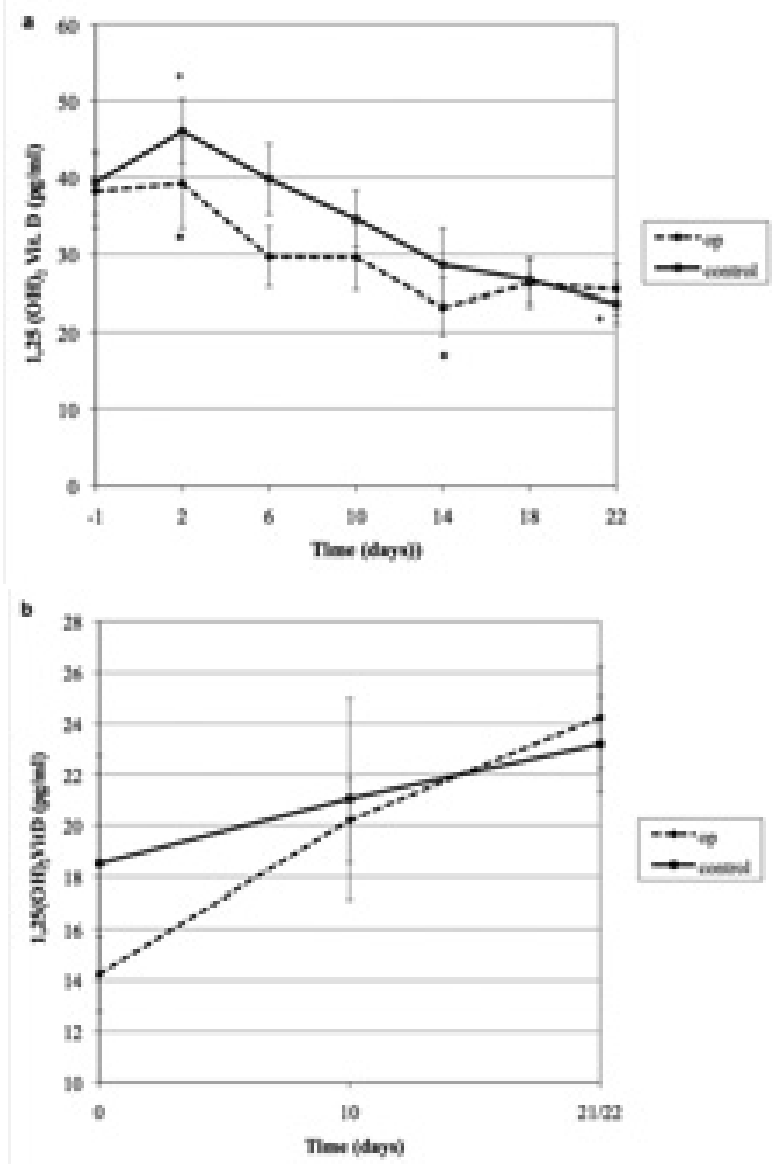

Fig. 2a, b Mean 1,25(OH) $)_{2}$ Vitamin D concentrations \pm STE in serum of the lambs (a) and foals (b) with surgery (op) and the control animals. ${ }^{*}$ significant decrease with time $(p<0.05)(a)$, from day 0 tp day $21 / 22$ in the foal op group $(p=0.043$
Foals

In the foals, the values increased in both groups, but were more prominent in the control group (Fig. 4b). The increasing values were due to an increased cartilage formation in the control group, while the cartilage resorption decreased in both groups. No group effects were evident in the foals.

Bone parameters in the lambs

Lambs

Total bone mineral density $\left(\mathrm{BMD}_{\text {tot }}\right)$ increased in all groups, wheras the increase in the op group with the time was significant. The control group only revealed a small increase, which was not significant. Cortical bone mineral content

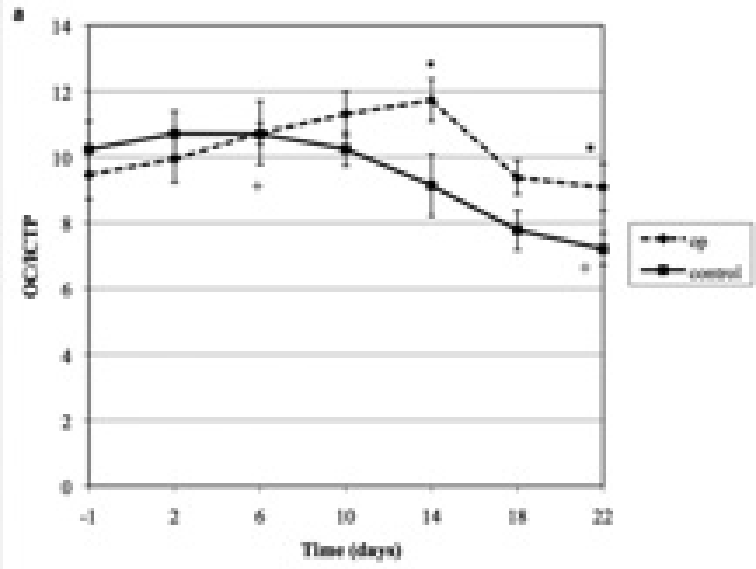

b

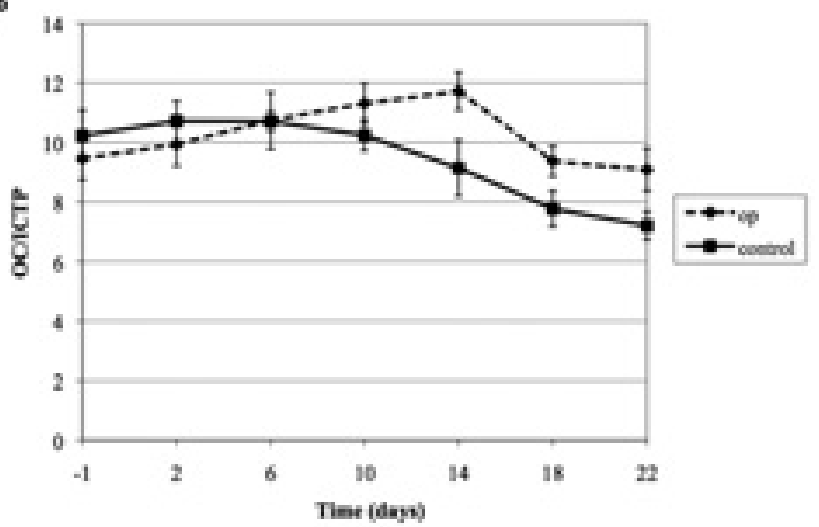

Fig. 3 a, b Values of the osteocalcin (OC) to ICTP (carboxyterminal telopeptide of type I collagen) ratio \pm STE in serum of the lambs with surgery (op) and the controls. *: significance within time in group op $(p=0.02)$

Table 1 Mean $\mathrm{pQCT}$ measurements \pm STE of the distal epiohysis of the tibia (before operation and 22 days later) total bone mineral density $\left(\mathrm{BMD}_{\text {tot }}\right)$, cortical density $\left(\mathrm{BMD}_{\text {crt }}\right)$, trabecular $\left(\mathrm{BMD}_{\text {trab }}\right)$, total bone mineral content $\left(\mathrm{BMC}_{\text {tot }}\right)$, coritcal $\left(\mathrm{BMC}_{\mathrm{cnt}}\right)$. trabecular $\left(\mathrm{BMC}_{\text {trab }}\right)$. * = significant difference, $\mathrm{p}=0.05)$ in time.

\begin{tabular}{lcccccc}
\hline \multicolumn{1}{c}{ Parameter } & \multicolumn{2}{c}{ operatated extremity } & \multicolumn{2}{c}{ contralateral extremity } & \multicolumn{2}{c}{ control } \\
\hline & $\mathrm{d}-1$ & $\mathrm{~d} 22$ & $\mathrm{~d}-1$ & $\mathrm{~d} 22$ & $\mathrm{~d}-1$ & $\mathrm{~d} 22$ \\
\hline $\mathrm{BMD}_{\text {tot }}\left(\mathrm{mg} / \mathrm{cm}^{3}\right)$ & $399.0 \pm 7.1$ & $440.4 \pm 13.6^{*}$ & $403.2 \pm 9.6$ & $439.0 \pm 14.3^{*}$ & $418.4 \pm 13.4$ & $427.7 \pm 15.1$ \\
$\mathrm{BMD}_{\text {crt }}\left(\mathrm{mg} / \mathrm{cm}^{3}\right)$ & $531.7 \pm 37.8$ & $520.0 \pm 10.9$ & $550.2 \pm 38.0$ & $515.0 \pm 12.4$ & $547.3 \pm 40.6$ & $497.5 \pm 14.4$ \\
$\mathrm{BMD}_{\text {trab }}\left(\mathrm{mg} / \mathrm{cm}^{3}\right)$ & $349.5 \pm 8.9$ & $330.6 \pm 10.4$ & $347.5 \pm 11.1$ & $339.9 \pm 14.2$ & $344.1 \pm 13.5$ & $336.6 \pm 16.5$ \\
$\mathrm{BMC}_{\text {tot }}\left(\mathrm{mg} / \mathrm{cm}^{3}\right)$ & $231.7 \pm 10.0$ & $228.5 \pm 8.0$ & $236.5 \pm 11.1$ & $236.7 \pm 8.6$ & $238.2 \pm 18.7$ & $226.8 \pm 12.4$ \\
$\mathrm{BMC}_{\text {crt }}\left(\mathrm{mg} / \mathrm{cm}^{3}\right)$ & $143.7 \pm 22.7$ & $181.2 \pm 9.3^{*}$ & $124.1 \pm 32.3$ & $189.2 \pm 11.7 *$ & $173.6 \pm 24.9$ & $177.3 \pm 14.2$ \\
$\mathrm{BMC}_{\text {trab }}\left(\mathrm{mg} / \mathrm{cm}^{3}\right)$ & $100.0 \pm 7.0$ & $77.2 \pm 3.1^{*}$ & $113.0 \pm 9.4$ & $82.6 \pm 4.0^{*}$ & $98.6 \pm 8.2$ & $79.1 \pm 5.0 *$ \\
\hline
\end{tabular}


Table 2 Mean $p Q C T$ measurements \pm STE of the distal epiphysis of the metatarsus

\begin{tabular}{lcccccc}
\hline \multicolumn{1}{c}{ Parameter } & \multicolumn{2}{c}{ operierte Gliedmaßen } & \multicolumn{2}{c}{ kontralaterale Gliedmaßen } & \multicolumn{2}{c}{ Kontrolle } \\
\hline & $\mathrm{d}-1$ & $\mathrm{~d} 22$ & $\mathrm{~d}-1$ & $\mathrm{~d} 22$ & $\mathrm{~d}-1$ & $\mathrm{~d} 22$ \\
\hline $\mathrm{BMD}_{\text {tot }}\left(\mathrm{mg} / \mathrm{cm}^{3}\right)$ & $336.5 \pm 13.0$ & $362.2 \pm 11.9$ & $325.8 \pm 14.9$ & $356.7 \pm 11.5$ & $332.4 \pm 12.2$ & $363.1 \pm 13.8$ \\
$\mathrm{BMD}_{\mathrm{ctr}}\left(\mathrm{mg} / \mathrm{cm}^{3}\right)$ & $338.8 \pm 9.6$ & $423.6 \pm 6.8$ & $429.8 \pm 9.4$ & $431.8 \pm 6.1$ & $418.9 \pm 7.9$ & $427.9 \pm 8.5$ \\
$\mathrm{BMD}_{\text {trab }}\left(\mathrm{mg} / \mathrm{cm}^{3}\right)$ & $291.2 \pm 20.2$ & $346.1 \pm 13.9$ & $283.0 \pm 18.1$ & $340.5 \pm 13.1$ & $323.3 \pm 18.3$ & $356.5 \pm 16.9$ \\
$\mathrm{BMC}_{\text {tot }}\left(\mathrm{mg} / \mathrm{cm}^{3}\right)$ & $121.3 \pm 9.5$ & $147.7 \pm 6.4$ & $117.0 \pm 8.7$ & $139.6 \pm 8.4$ & $132.6 \pm 11.0$ & $150.8 \pm 7.7$ \\
$\mathrm{BMC}_{\mathrm{ctr}}\left(\mathrm{mg} / \mathrm{cm}^{3}\right)$ & $70.6 \pm 10.4$ & $91.6 \pm 11.1$ & $58.5 \pm 9.6$ & $86.3 \pm 9.7$ & $67.7 \pm 14.1$ & $90.4 \pm 10.6$ \\
$\mathrm{BMC}_{\text {trab }}\left(\mathrm{mg} / \mathrm{cm}^{3}\right)$ & $49.8 \pm 4.9$ & $63.4 \pm 3.2$ & $47.5 \pm 4.5$ & $60.0 \pm 4.0$ & $57.7 \pm 5.6$ & $66.3 \pm 3.7$ \\
\hline
\end{tabular}
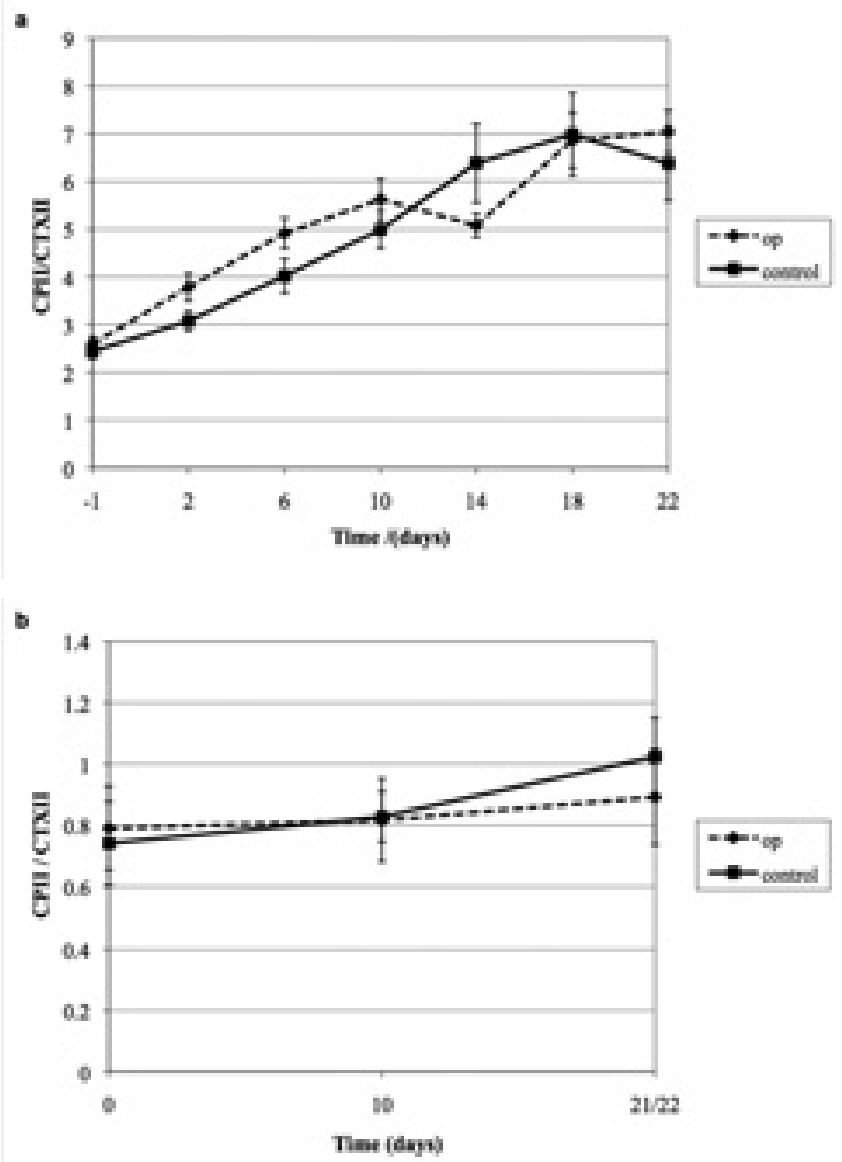

Fig. 4 a, b Valus of the CPII (cartilage formation marker) to CTX-II (cartilage resorption marker) in serum of operated and control animals; $a=$ lambs, *: significant difference from day - 1 to 22 in op group ( $p=0.005)$. + : significant time difference in control group from day -1 to 18 ( $p=0.007, b=$ foals.
$\left(\mathrm{BMC}_{\mathrm{crt}}\right)$ increased with time in the operated animals, whereas the trabecular content $\left(\mathrm{BMC}_{\text {trab }}\right)$ significantly decreased in all groups (Table 1).

In the metatarsus a significant increase in all groups was observed for $\mathrm{BMD}_{\text {trab }}$ as well as $\mathrm{BMC}_{\text {trab }}$. In contrast, to the $\mathrm{BMC}_{\text {trab }}$ of the tibia, which decreased over time, the values in the metatarsus increased (Table 2) in all groups. No significant group effect could be revealed.

In the metacarpus (Table 3) all groups showed a significant increase of the mineral parameters over time. $\left(\mathrm{BMC}_{\text {tot' }^{\prime}}\right.$ $\left.\mathrm{BMC}_{\mathrm{cr}}, \mathrm{BMC}_{\text {trab }}\right)$. In the control group no significant time effect was noticed as well as no group effect.

\section{Immunhistochemistry}

Lambs

All bone samples of the operated extremity, with the exception of PTHR- and TGF $\beta$-marked slides, were stained notably more often and significantly more intensive compared to the controls. The Ihh stained samples showed the most notable staining differences within the different cuttings and the zones of the cartilage of the growth plate. $86 \%$ of all samples from the operated extremity could be judged, whereas in the controls only $80 \%$ of the samples were stained. The intensity of the staining was at a rate of 2.77 compared to controls, the average values in the op group were from 3.11 with a maximum of 12 .

The comparison of the staining intensitiy of Ihh was significantly different between the op group and the control group in zone 1 , which was the lateral side of the bones $(P=0.04)$. There were significant differences between the different zones, especially in zone 2 the columnar cartilage was stained were weakly. The operation mainly influenced the Ihh expression (Table 4.) The slides were mainly stained on the lateral side of the bone, most

Table 3 Mean pQCT measurements \pm STE of the distal epiohysis of the metacarpus

\begin{tabular}{lcccccc}
\hline \multicolumn{1}{c}{ Parameter } & \multicolumn{2}{c}{ operated extremity } & \multicolumn{2}{c}{ contralateral extremity } & \multicolumn{1}{c}{ control } \\
\hline & $\mathrm{d}-1$ & $\mathrm{~d} 22$ & $\mathrm{~d}-1$ & $\mathrm{~d} 22$ & $\mathrm{~d}-1$ & $\mathrm{~d} 22$ \\
\hline $\mathrm{BMD}_{\text {tot }}\left(\mathrm{mg} / \mathrm{cm}^{3}\right)$ & $327.4 \pm 15.6$ & $357.4 \pm 10.2$ & $339.8 \pm 11.0$ & $353.6 \pm 12.3$ & $339.3 \pm 14.6$ & $347.2 \pm 12.5$ \\
$\mathrm{BMD}_{\mathrm{ctr}}\left(\mathrm{mg} / \mathrm{cm}^{3}\right)$ & $419.7 \pm 9.1$ & $426.2 \pm 7.0$ & $415.5 \pm 7.0$ & $425.5 \pm 10.4$ & $418.3 \pm 10.0$ & $420.3 \pm 6.1$ \\
$\mathrm{BMD}_{\text {trab }}\left(\mathrm{mg} / \mathrm{cm}^{3}\right)$ & $310.1 \pm 17.3$ & $336.6 \pm 12.3$ & $324.5 \pm 11.3$ & $347.8 \pm 15.4$ & $317.0 \pm 18.5$ & $340.8 \pm 12.6$ \\
$\mathrm{BMC}_{\text {tot }}\left(\mathrm{mg} / \mathrm{cm}^{3}\right)$ & $133.8 \pm 9.4$ & $154.4 \pm 6.0$ & $143.0 \pm 5.0$ & $160.0 \pm 7.3$ & $143.9 \pm 12.1$ & $157.0 \pm 8.9$ \\
$\mathrm{BMC}_{\mathrm{ctr}}\left(\mathrm{mg} / \mathrm{cm}^{3}\right)$ & $70.2 \pm 12.9$ & $97.4 \pm 8.5$ & $78.5 \pm 8.7$ & $97.2 \pm 13.6$ & $86.5 \pm 12.7$ & $91.7 \pm 10.0$ \\
$\mathrm{BMC}_{\text {trab }}\left(\mathrm{mg} / \mathrm{cm}^{3}\right)$ & $57.2 \pm 4.6$ & $65.6 \pm 3.4$ & $61.6 \pm 2.8$ & $69.2 \pm 3.4$ & $60.5 \pm 6.3$ & $68.3 \pm 4.5$ \\
\hline
\end{tabular}


Table 4 P-Values of the different zones and different factors. Op = operated animals, Bone $=$ differences between the different bones. IZ $=$ zone.

\begin{tabular}{|c|c|c|c|c|c|c|c|}
\hline TotlZ-Ihh & Sig. $p$ & IZ1-Ihh & Sig. $p$ & IZ2-Ihh & Sig. $p$ & IZ3-Ihh & Sig.p \\
\hline OP vs Control & 0,66 & OP vs Control & 0,04 & OP vs Control & 0,96 & OP vs Control & 0,5 \\
\hline Bone & 0,66 & Bone & 0,5 & Bone & 0,5 & Bone & 0,5 \\
\hline OP vs Control * Bone & 0,88 & OP vs Control * Bone & 0,93 & OP vs Control * Bone & 0,18 & OP vs Control * Bone & 0,27 \\
\hline TotIZ- FGF & Sig. $p$ & IZ1-FGF & Sig. $p$ & IZ2-FGF & Sig. $p$ & IZ3-FGF & Sig.p \\
\hline OP vs Control & 0,11 & OP vs Control & 0,6 & OP vs Control & 0,08 & OP vs Control & 0,87 \\
\hline Bone & 0,35 & Bone & 0,62 & Bone & 0,72 & Bone & 0,41 \\
\hline OP vs Control * Bone & 0,8 & OP vs Control * Bone & 0,17 & OP vs Control * Bone & 0,81 & OP vs Control * Bone & 0,64 \\
\hline TotIZ-PTHR & Sig. $p$ & IZ1-PTHR & Sig. $p$ & IZ2-PTHR & Sig. $p$ & IZ3-PTHR & Sig.p \\
\hline OP vs Control & 0,26 & OP vs Control & 0,54 & OP vs Control & 0,09 & OP vs Control & 0,32 \\
\hline Bone & 0,13 & Bone & 0,23 & Bone & 0,2 & Bone & 0,48 \\
\hline OP vs Control * Bone & 0,82 & OP vs Control * Bone & 0,5 & OP vs Control * Bone & 0,85 & OP vs Control * Bone & 0,52 \\
\hline TotIZ-PTHrP & Sig. $p$ & IZ1-PTHrP & Sig. $p$ & IZ2-PTHrP & Sig. $p$ & IZ3-PTHrP & Sig.p \\
\hline OP vs Control & 0,31 & OP vs Control & 0,5 & OP vs Control & 0,58 & OP vs Control & 0,5 \\
\hline Bone & 0,15 & Bone & 0,5 & Bone & 0,58 & Bone & 0,27 \\
\hline OP vs Control * Bone & 0,7 & OP vs Control * Bone & 0,38 & OP vs Control * Bone & 0,67 & OP vs Control * Bone & 0,4 \\
\hline
\end{tabular}

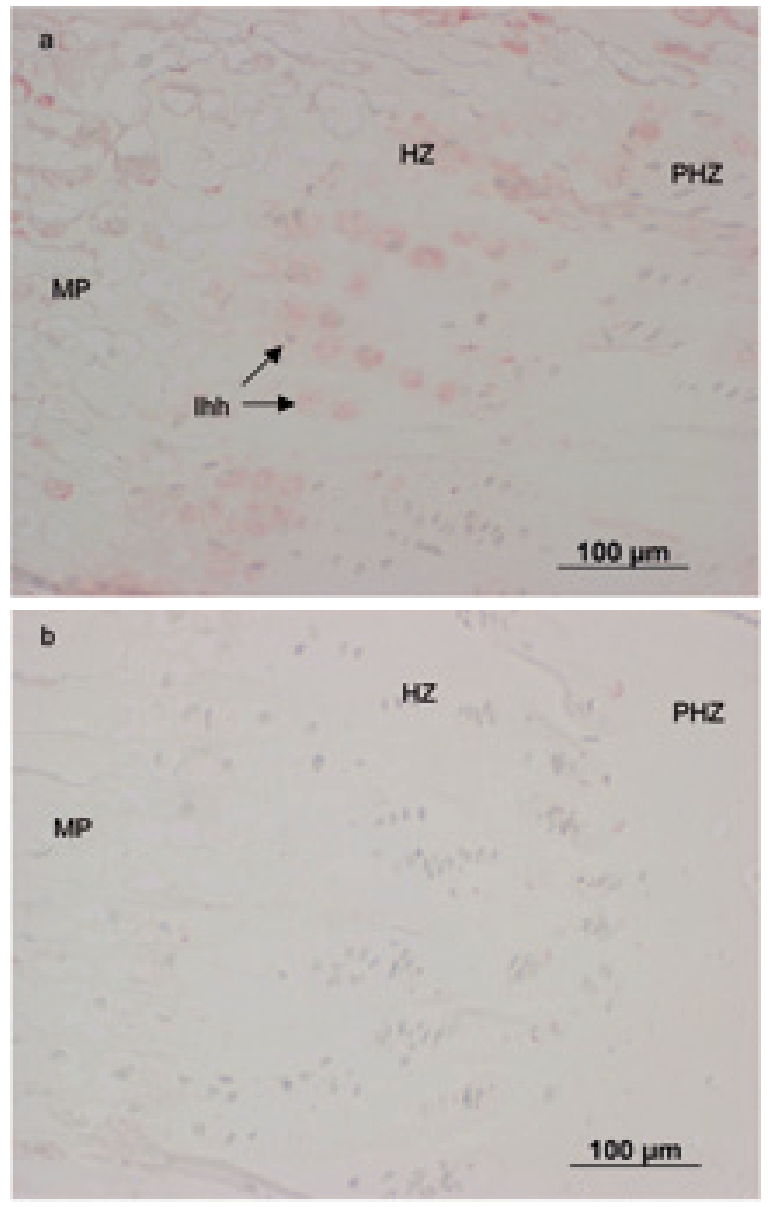

Fig. 5 Frontal cut through the epiphyses (radius). Immunohistochemistry of Ihh, expression of thh in red on the operated lateral side (a) while no immunostaining is visible at the medial non-operated side of the radius (b). Ihh is upregulated in the hypertrophic zone (HPZ) close to the metaphysis (MP), less in the prehypertrophic zone (PHZ). (Paraffine section, antibodies Ihh, 100x). intensively in the proliferative and hypertrophic zone of the growth plate. There were differences between the different bones, such that the tibia showed a more significant staining and more cells compared to the metatarsus of the same animal (Fig. 5).

\section{Discussion}

The method of "hemicircumferential transection of the periosteum and periosteal stripping" (HCTP and PS) has been widely used in foals with axial deviations since 1982 (Aver and Martens). The mechanisms have been described by Aver und von Rechenberg (2006). The authors assumed that mainly locally the growth factors are responsible for the increased growth and therewith the correction of the axial deviations. The goal of the present study was to evaluate a possible effect of periost stripping on systemic, but also local factors and bone structure using growing lambs as a model. In addition, foals were used to determine systemic effects.

In the present study, only few foals with naturally occuring axial deviations could be used. The foals were all privately owned. For this reason no further investigations could be performed on these animals. For this reason, lambs were used as a model for the foals. One advantage of this experimental study was, that all parameters were standardized. In addition, at the end of the study, the bones could be used for immunohistochemical analysis with at least 6 lambs per group and at the same time point. Lambs strain their extremities similar to foals after surgery and are useful model animals (Nunamaker 1998). The disadvantage of the used lambs was, that they did not show axial deviations before surgery.

The foals of this study showed no differences between the operated group and the control group when looking at the 
bone and cartilage markers. In a study with foals on osteochondrosis, Vervuert et al. (2007) showed no differences between animals with osteochcondrosis compared to those without when comparing the osteocalcin concentrations in serum, which is a bone formation marker. In contrast, Billinghurst et al. (2004) demonstrated that bone marker concentrations differ between diseased and healthy animals in the first year of the foal's life. In addition, Garnero et al. (2001 b) detected higher osteocalcin and crosslaps concentrations in patients with osteoarthrosis in the stifle joint compared to healthy individuals. In the lambs of the present study, no significant changes of the bone markers was observed after surgery, although a tendency towards a higher bone remodeling rate was seen. With these results, however, it has to be kept in mind that the operation is locally restricted to the periost and no intraarticular interventions were done. This may be also true for the foals, although the foals of the operated group showed axial deviations before the intervention. A possible explanation for this may be that bone metabolism is not influenced by this strictly local intervention and the intervention is much too minimal to stimulate real signaling bone parameters systemically. Another possible explanation may be that the bone marker concentration may be increased after a longer time than just 3 weeks post surgery. The same may be true for the cartilage markers. The above mentioned studies deal with subjects, which have been diseased over months and years. There, a significant decrease of the bone markers was observed over time, which seems to be physiological, since this has already been shown in other studies (Price et al. 2001, Vervuert et al. 2007, Hüttenmoser (2006).

Under physiological circumstances, 1,25(OH) 2 Vitamin D plays a minor role in the influence on bone, but increases the absorption of calcium and phosphorus. The latter are essential for the mineralization of bone (Erben 2000, Ballock und O'Keefe 2003). With the periosteal stripping an increased bone formation and, therewith, mineralization was expected. The concentrations in serum did not reveal significant differences between the groups. Again, this may be due to the fact that the amounts of minerals (calcium, phosphorus) needed to accomplish the increased mineralization were too low to disturb the homoestasis of $1,25(\mathrm{OH})_{2}$ VitD-PTH. Both lamb groups revealed decreased serum concentrations of $1,25(\mathrm{OH})_{2} \mathrm{VitD}$, which was also shown in a study of Hüttenmoser (2006) and Chanetsa et al. (2000). In the foals a significant difference between the diseased and healthy foals existed at the beginning of the study. The lower $1,25(\mathrm{OH})_{2} \mathrm{VitD}$ concentrations in the diseased foals may be accounted for low $\mathrm{Ca}$ and $\mathrm{P}$ concentrations to mineralize the bone in the epiphysis and therefore no proper growth was possible. The OC/ICTP ratio showed that a difference in bone formation in the different groups existed although this difference was not significant. The ratio increased in the first 14 days in the operated animals. Despite missing significance, this showed, that post surgery the bone is remodeled more prominent and new bone is formed. This may be a consequence of the surgery, which should lead to increased remodeling of the growth plate and subsequent increased growth in length of the bones. However, it has to be kept in mind that the lambs only survived for 22 days after the surgery. It is not clear what would have happened if more lambs would have been kept for a longer period. Accordingly also the foals revealed an increa- sed ratio, which shows increased bone formation. This may lead to the assumption that bone formation is upregulated if "periostal stripping" is used as therapy in foals with axial deviation.

The ratio of CPII/CTX-II, which is corresponding to increasing cartilage remodeling did not give any further information, since it was increasing with time in both species in both groups, which seems to be normal for growing animals (Billinghurst et al. 2003).

Bone mineral density and content also could not differentiate significantly between groups, although tendencies were also observed. An increase with time was evident in the operated groups. This increase may be physiological, since also Hüttenmoser (2006) characterized the same results in growing lambs. This is probably true, because growing animals in the first months of life mineralize and condensate bone to deal with the higher body mass and strain that are acting on their bones.

The results of the immunohistochemistry showed that periostal stripping influences the "up- and down-regulation" of different bone growth associated factors and there, mainly lhh. The scoring of the operated bones clearly revealed higher scoring results in these bones confirming earlier studies performed with lambs on consecutive days at our laboratory (von Rechenberg 2010). There, Ihh, PTHrP, PTHR, FGF and TGF were scored in radii and tibiae at 2, 6, 10, 14, 18 and 22 days. These bone sections were cut in dorso-palmar fashion close to the surgery site of the periosteal stripping. In the current study, histology sections were prepared in mediolateral fashion such that unoperated and operated site could be compared within the same bone and only at one time point (22 days). Although signal transduction could not be followed over time, immunhistochemical stainings were increased at the surgery site also in the current study similar to the other study, where Ihh was also upregulated. Interestingly, up-regulation was not the same in all bones. Especially the metatarsal and metacarpal bones were different from the radii and tibiae. The different effect of the surgery on the different bones may be due to the different course of the signaling concentrations of the factors according to physiological stage and closure, respectively ossification in the growth plates. In different stages of the development of the growth plate, the reaction to the stimuli may therefore partly be retarded or not as pronounced. The less intense staining in the cells of the epiphysis in the metarsus compared to the tibia may be explained such that bone maturation is completed earlier compared to the tibia (Fretz et al. 1984) and therefore, the increased growth stage is already finished at this age. Different closure time of growth plates is also the reason, why Aver and von Rechenberg (2006) generally suggest operating the foals before 3 months of age.

In conclusion, although a higher bone formation was revealed in this study, the systemic factors seem to be only minimally influenced by periostal stripping. Longitudinal growth of long bones seems to be mainly a local event. Immunohistochemical changes in signal transduction also in this study support, however, that periosteal stripping is directly responsible for growth by interruption of the cross talk between periost and growth plate. 


\section{References}

Aver J. A. and Martens R. J. (1982) Periosteal transection and periosteal stripping for correction of angular limb deformities in foals. Am. J. Vet. Res. 43, 1530-1534

Auer J. A. (2004) Diagnose und Behandlung von Achsenfehlstellungen bei Fohlen. Skriptum für Studierende der Vetsuisse-Fakultät der Universität Zürich

Auer J. A. and von Rechenberg B. (2006) Treatment of angular limb deformities in foals. Clin. Tech. Equine Pract. 5, 270-281

Ballock R. T. and O'Keefe R. J. (2003) Physiology and pathophysiology of the growth plate. Birth Defects Res. (Part C) 69, 123-143

Billinghurst R. C., Brama P. A. J., van Weeren P. R., Knowlton M. S. and Mcllwraith C.W. (2003) Significant exercise-related changes in the serum levels of two biomarkers of collagen metabolism in young horses. Osteoarhtritis Cartilage 11, 760-769

Billinghurst R. C., Brama P. A. J., van Weeren P. R., Knowlton M. S. and Mcllwraith C. W. (2004) Evaluation of serum concentrations of biomarkers of skeletal metabolism and results of radiography as indicators of severity of osteochondrosis in foals. Am. J. Vet. Res. 65, 143-150

Bushinsky D. A. and Monk R. D. (1998) Calcium. Lancet, 352: p 306-311

Caron J. P. (1988) Angular limb deformities in foals. Equine Vet. J. $20,225-228$

Chanetsa F., Hillman L. S., Thomas M. G. and Keisler D. H. (2000) Estrogen agonist (Zeranol) treatment in a castrated male lamb model: Effects on growth and bone mineral accredtion. J. Bone Miner. Res. 15, 1361-1367

Faulkner K. G., Glüer C. C. and Majumar S. (1991) Noninvasive meausrments of bone mass, structure, and strength: current methoda and experimental techniques. Am. J. 157, 1229-1237

Frisbie D. D., Ray C. S., lonescu M., Poole A. R., Chapman P. L. and Mcllwraith C. W. (1999) Measurement of synovial fluid and serum concentratons of the 846 epitope of chondroitin sulphate and of carboxy propeptides of type II procollagen for diagnosis of osteochondral fragmentation in horses. Am. J. Vet. Res. 60, 306-309

Fretz P. B., Cymbaluk N. F. and Pharr J. W. (1984) Quantitative analysis of long-bone growth in the horse. Am. J. Vet. Res. 45, 16021609

Gasser J. A. (1995) Assessing bone quantity by pQCT. Bone 17 Suppl., 145S-154S

Garnero P., Borel O. and Delmas P. D. (2001) Evaluation of a fully automated serum assay for $C$-terminal cross-linking telopeptide of type I collagen in osteoporosis. Clin. Chem. 47, 694-702

Hüttenmoser D. (2007) Einfluss der Alpung auf den Knochenstoffwechsel bei wachsenden Schafen. Dissertation Vetsuisse-Fakultät Universität Zürich
Laverty S., lonescu M., Marcoux M., Bouré L., Doizé B. and Poole A. R. (2000) Alterations in cartilage type-Il procollagen and aggrecan contents in synovial fluid in equine osteochondrosis. J. Orthop. Res. 18, 399-405

Lepage O. M., D. J. Hartmann, R. Eicher, B. Uebelhart, P. Tschudi and D. Uebelhart (1998) Biochemical markers of bone metabolism in draught and warmblood horses. Vet. J. 156, 169-175.

Liesegang A., Sassi M.-L., Risteli J., Eicher R., Wanner M. and Riond J.-L. (1998) Comparison of bone resorption markers during hypocalcemia in dairy cows. J. Dairy Sci. 81, 2614-2622

Liesegang A. (2000) Anwendung von Knochenmarkern in der Veterinärmedizin. Schweiz. Arch. Tierheilk. 142, 613-623

Liesegang A. and Risteli J. (2005) Influence of different calcium concentrations in the diet on bone metabolism in growing dairy goats and sheep. J. Anim. Physiol. Anim. Nutr. 89, 113-119

Nilsson O., Marino R., De Luca F., Philipp M. and Baron J. (2005) Endocrine regulation of the growth plate. Horm. Res. 64, 157 165

Nunamaker D. M. (1998) Experimental models of fracture repair. Clin. Orthop. Relat. Res. 335 Suppl., 56-65

Price J. S., Jackson B. F., Gray J. A., Harris P. A., Wright I. M., Pfeiffer D. U., Robins S. P., Eastell R. and Ricketts S. W. (2001) Biochemical markers of bone metabolism in growing thoroughbreds: a longitudinal study. Res. Vet. Sci. 71, 37-44

Stevens D. A. and Williams G. R. (1999) Hormone regulation of chondrocyte differentiation and enchondral bone formation. Mol. Cell. Endocrinol. 151, 195-204

Van der Eerden B. C. J., Karperien M. and Wit J. M. (2003) Systemic and local regulation of the growth plate. Endocr. Rev. 24, 782801

Vervuert I., Winkelsett S., Christmann L., Bruns E., Hoppen H-O., Distl O., Hertsch B. and Coenen M. (2007) Evaluation of the influences of exercise, birth date, and osteochondrosis on plasma bone marker concentrations in Hanoverian Warmblood foals. Am. J. Vet. Res 68, 1319-1323

Vortkamp A. (2006) Regulation der Chondrozytendifferenzierung in der Wachstumsfuge: Parakrine Signalsysteme. In: Ganten D., Rukkpaul K. (Hrsg.): Molekularmedizinische Grundlagen von paraund autokrinen Regulationsstörungen. Springer-Verlag Berlin Heidelberg, Deutschland, pp 461-477

PD Dr. Annette Liesegang

Institute of Animal Nutrition

Vetsuisse Faculty Zurich

University of Zurich

Switzerland

aliese@vetphys.uzh.ch 